\title{
Custos e formação do preço de vendas em hotéis
}

\section{Costs and pricing in hotel sales}

\author{
Suzete Antonieta Lizote Doutora em Administração. Universidade do Vale do Itajaí (UNIVALI) - Brasil. lizote@univali.br \\ Sayonara de Fátima Teston Doutora em Administração. Universidade do Oeste de Santa Catarina (UNOESC) - Brasil. \\ sayo@unoesc.edu.br \\ Grazieli Vitali Mestranda em Administração. Universidade do Vale do Itajaí (UNIVALI) - Brasil. \\ grazielivitali@gmail.com \\ Charlize de Morais Noval Mestranda em Administração. Universidade do Vale do Itajaí (UNIVALI) - Brasil. \\ charlize.n@gmail.com
}

\section{RESUMO}

Para competir no contexto ambiental presente, no qual o gerenciamento eficiente dos custos é determinante, adotar uma abordagem empreendedora na elaboração de estratégias torna-se um fator essencial para o sucesso das empresas. Com esse entendimento, a presente pesquisa tem como objetivo avaliar a relação entre o desempenho organizacional e o gerenciamento dos custos dos hotéis. Metodologicamente, quanto aos seus objetivos, classifica-se como descritiva e em relação à abordagem do problema, foi quantitativa. Os dados obtiveram-se junto a 26 hotéis localizados em Balneário Camboriú e Itajaí/SC por meio de uma survey com questionário, que levantava a percepção dos gestores. Os custos foram trabalhados segundo o método utilizado para estimá-los, o critério de precificação da diária, os principais custos de hospedagem e em relação a sua utilidade. Para a análise dos resultados foi empregada a Análise de Variância (ANOVA). Os resultados deste estudo evidenciaram que os hotéis que adotam o método de custeio baseado em atividades e formam o preço considerando os valores de mercado são os que possuem respectivamente maior desempenho. Confirma-se que a prática de custos não tem correlação com o desempenho.

Palavras-chave: Custos. Desempenho. Preço de venda.

\begin{abstract}
To compete in the present economic context, where efficient cost management is crucial, adopting an entrepreneurial approach to establishing strategies becomes an essential factor for business success. With such understanding, this research aims to evaluate the relationship between organizational performance and hotel cost management. Methodologically, regarding its objectives, it is classified as descriptive and in relation to the approach of the problem, it is quantitative nature. The data were obtained from 26 hotels located in Balneário Camboriú and Itajaí / SC through a survey with a questionnaire, which analysed the perception of managers. The costs were worked out according to the method used to estimate them, the daily price criterion, the main hosting costs and their usefulness. For the analysis of the results, Analysis of Variance (ANOVA) was used. The results of this study showed that hotels that adopt the activity-based costing method and form the price considering market values are the ones that have the highest performance. It was confirmed that cost practice has no correlation with performance.
\end{abstract}

Keywords: Costs. Performance. Sale price. 


\section{INTRODUÇÃO}

A gestão de custos é uma importante ferramenta para a tomada de decisões nas empresas. Os efeitos de suas decisões serão percebidos tanto no presente quanto em longo prazo e ainda estarão resguardadas na escolha da alternativa que proporciona maior vantagem competitiva. Tal afirmação é amparada por Bruni e Famá (2004, p. 237) "a ênfase da análise de custos deve estar baseada nas decisões tomadas e seus efeitos subsequentes". Nota-se, que é de grande importância a geração das informações, assim como o seu uso eficaz e o fornecimento de subsídios durante todo o processo da gestão dos negócios. Hansen e Mowen (2001, p. 31) evidenciam que "Com a sua procura por melhores informações e produtividade, o setor de serviços aumentará a sua demanda por informações de gestão de custos".

Destaca-se também que entre os temas mais estudados no âmbito da administração estratégica encontra-se o desempenho organizacional e que na sua análise têm sido utilizadas diversas aproximações. Dentre elas, uma que vem ganhando importância é a orientação empreendedora que as firmas manifestam, pois se refere aos processos estratégicos que possibilitam às organizações dispor de uma base para definir sua tomada de decisões. Portanto, nos debates sobre estratégia, teoria das organizações e empreendedorismo, cada vez mais pesquisas mostram que o desempenho organizacional e a sustentabilidade dos negócios são influenciados positivamente pela capacidade de empreender e inovar.

O Brasil está em $13^{\circ}$ lugar na economia turística do mundo (MINISTÉRIO DO TURISMO, 2017) e tem potencial para o desenvolvimento e crescimento. Porém, ter atrativo ou potencial turístico não é suficiente para que a atividade se desenvolva e traga benefícios. É necessário que haja planejamento e gestão eficiente do setor. O melhor preço poderá decidir o sucesso ou o fracasso do empreendimento turístico, pois é por meio dele que irá atrair e fidelizar os clientes, e é por meio do preço que o estabelecimento saberá se está obtendo lucros ou amargando prejuízos (LEITÃO; SILVA, 2006).

No ramo hoteleiro, Castillo e Quintero (2013) salientam que a maximização de receitas favorece o gerenciamento eficaz entre administração de demanda e o faturamento. Segundo os autores, isso ocorre porque envolve a seleção e o uso de ferramentas de marketing para trazer ao meio de hospedagem o marketing mix desejado, fundamental, para analisar o mercado, a concorrência e desenvolver preços e tarifas para cada segmento.

Entretanto, um aspecto que não tem sido considerado com a mesma ênfase nas pesquisas é como os métodos de custeio e os mecanismos de precificação se relacionam o desempenho das organizações. Diante deste contexto surge a pergunta que norteia a presente pesquisa: Que relações se verificam o desempenho organizacional e o gerenciamento dos custos dos hotéis? Para respondê-la definiu-se como objetivo geral, avaliar a relação entre o desempenho organizacional e o gerenciamento dos custos dos hotéis. Para realizar a análise das associações entre os referidos constructos se estabeleceram os seguintes objetivos específicos: mensurar o desempenho por meio da percepção dos gestores em comparação aos concorrentes mais próximos; e, avaliar se o gerenciamento de custos influencia na relação entre os constructos ou neles individualmente.

Com o presente estudo buscou-se obter novas evidências empíricas sobre as relações entre os construtos mencionados. Sua consecução, além de original para as organizações - foco da pesquisa, ao trazer como um dos determinantes o gerenciamento dos custos - possui relevância prática para a melhoria do funcionamento dos hotéis. Por outro lado, as proposições de articulações teóricas, ainda pouco trabalhadas em estudos empíricos da realidade brasileira justificam o interesse acadêmico.

\section{FUNDAMENTAÇÃO TEÓRICA}

Nesta seção apresenta-se o marco teórico definido como necessário à compreensão da abordagem adotada. 


\subsection{Gestão de Custos}

A gestão de custos vem ganhando cada vez mais importância nas empresas devido a grande concorrência existente na maior parte dos mercados na atualidade. Isto torna difícil para a organização definir seus preços de venda e, portanto, segue o preço definido pelo "mercado". Assim, a gestão de custos possibilita aos administradores ter uma visão mais realista e um meio de melhor gerenciá-los, tornando possível concorrer em mercados altamente competitivos através da sua redução (KOLIVER, 2009). Algumas ferramentas são imprescindíveis para essa finalidade, incluindo os métodos de custeio, os quais permitem a correta alocação dos custos incorridos pela empresa.

No caso de serviços, torna-se difícil mensurar a sua importância, como também de fazer atribuição de valores. Para Perez Jr., Oliveira e Costa (2005, p. 338), "a prestação de serviços, quase sempre envolve aspectos intangíveis, diferentemente da produção física de determinado produto material ou tangível". Essas informações são essenciais para o planejamento de ações futuras, além de comunicar aos gestores os dados de origem econômica e financeira da instituição. Neste cenário, Hansen e Mowen (2001, p. 34) contribuem relatando que "a mensuração e os relatórios de custos da qualidade são características-chaves dos sistemas de gestão de custos tanto para setores de manufatura quanto de serviços". Com a mensuração, os administradores podem efetuar o controle dos custos, visando determinar a rentabilidade da empresa. $O$ controle, assim como o planejamento em qualquer instituição, é indispensável. Lunkes $(2009$, p. 346) enfatiza que "Os hotéis que entendem a necessidade de criar valor têm como grande desafio encontrar formas de operacionalizar os novos métodos de gestão, como os relacionados a custos".

Hansen e Mowen (2001, p. 123) descrevem que "os gestores devem ser capazes de rastrear os custos dos serviços prestados tão precisamente quanto devem rastrear os custos dos produtos manufaturados". As instituições que priorizarem o tempo, a qualidade e a eficiência na produção de bens ou na execução de seus serviços, agregarão valor ao produto e, desta forma, alcançarão a vantagem competitiva para com seus concorrentes. Consoante a isso, eles reforçam que "para assegurar e manter uma vantagem competitiva, os gestores enfatizam o tempo, a qualidade e a eficiência." (HANSEN; MOWEN 2001, p. 31).

A formação de preços foi uma das primeiras ferramentas criadas pela teoria dos custos, demonstrando seu papel fundamental, já que antes da sua existência era impossível calcular o custo de um produto ou serviço, elemento considerado essencial para formar o preço ou valor de venda de um produto. Atualmente, a realidade das empresas quanto à formação de preços modificou-se, já que o mercado globalizado força também às empresas a adaptar seus preços ao que é praticado pelos seus concorrentes. Neste sentido, Leite, Lamas e Nóbrega (2019) esclarecem que a formação de preço se apresenta como uma variável importante a ser considerada, pois se não for gerenciada adequadamente, a precificação pode invalidar a vantagem competitiva de uma empresa, não importando quão diferente ela possa ser em outros aspectos.

Ainda, existe outra corrente que acredita ser o preço uma função do valor percebido pelo consumidor ao invés de ser relacionado ao custo de produção (BEULKE; BERTÓ, 2001). De forma complementar Viana Filho, Gomes e Souza (2011) descrevem que os preços de venda definidos pelas entidades sugerem a estratégia e a finalidade desejada por ela. Dentre as que incluem: sustentar sua posição no mercado, aumentar seu market share em determinado segmento do mercado, tornarem-se competitivas ou, tentarem sobreviver. Diante disso, a consciência quanto ao custo de se realizar um serviço não perdeu valor, e sim se alterou a visão a respeito dele. Na atual conjuntura os custos passam "a constituir um piso do preço e elemento absolutamente decisivo para a avaliação do desempenho de produtos, mercadorias e serviços" (BEULKE; BERTÓ, 2001, p. 21).

Bruni e Fama (2004, p. 321) citam alguns dos principais objetivos quando da utilização das metodologias para formação de preços, sendo eles: proporcionar o maior lucro possível no longo prazo; maximizar a participação de mercado de forma lucrativa; maximizar a capacidade produtiva de forma a reduzir a ociosidade e as despesas operacionais; e, maximizar a rentabilidade do capital empregado para perpetuar os negócios de forma autossustentável.

Lunkes (2009) investigou sobre a existência de informações de custos em empresas hoteleiras da cidade de Florianópolis (SC). Os resultados revelam que $40 \%$ dos hotéis utilizam algum sistema de custeio. 0 estudo de Santos e Flores (2017) analisou as estratégias de formação de preços nos meios de hospedagem em São Luís/Maranhão/Brasil. A pesquisa aponta que são utilizadas as ferramentas e estratégias de gestão de 
preços recomendados pela legislação e outras de apoio para gestão dos preços e que há um esforço da gestão dos hotéis para profissionalizar os métodos de cálculo da diária, utilizando técnicas que Ihes deem maior segurança na decisão e formação de preços, abandonando os métodos informais ou empíricos, sem abandonar a pesquisa de mercado.

\subsection{Desempenho Organizacional}

A avaliação de desempenho serve para controlar uma estratégia definida pela organização, confrontando seu resultado com os objetivos estabelecidos. Nesta ótica Neely, Gregory e Platts (2005) a veem como um processo de quantificação da eficiência e efetividade das ações empresariais. Para Igarashi et al. (2008) é mediante a análise do desempenho que as organizações podem medir a sua capacidade de sobrevivência e continuidade, face às exigências do ambiente interno e externo em que estejam inseridas. Macedo e Corrar (2010), por sua vez, destacam que a avaliação do desempenho das empresas tem se destacado na gestão das organizações, pois seja contábil ou de mercado, é fundamental para sua sobrevivência. Sua análise, segundo Brandt, Kroenke e Pletesch (2018) é de suma importância, por ser essencial para o controle gerencial dos negócios.

O crescimento do interesse pelas medidas de desempenho organizacional deve-se às importantes mudanças tanto no ambiente empresarial quanto nas estratégias adotadas. Neste sentido, Ramos e Souza $(2018$, p. 43) esclarecem que "A avaliação de desempenho das organizações é uma atividade essencial na gestão, pois os novos desafios, complexidade de relações e a dinâmica do mundo dos negócios cada vez mais tecnológica e competitiva".

No que tange a sua mensuração, Gunasekaran e Kobu (2007) consideram um grande desafio para os administradores o desenvolvimento de medidas apropriadas para a tomada de decisões que contribuam para o alcance da competitividade. O desempenho pode ser mensurado através de duas perspectivas: primeiramente como conceito subjetivo, o qual está relacionado ao desempenho das organizações segundo a sua própria expectativa ou relativamente à concorrência (PELHAM; WILSON, 1996). A segunda opção é analisá-lo pelo método objetivo, baseado em medidas absolutas de desempenho (CHAKRAVARTHY, 1996).

Para dar suporte às decisões estratégicas da organização sua mensuração, segundo Bortoluzzi, Ensslin e Ensslin (2010), deve considerar alguns elementos importantes, quais sejam: levar em consideração as particularidades de cada organização; considerar indicadores financeiros e não financeiros, ou seja, os aspectos tangíveis e intangíveis; ligar os objetivos estratégicos com os objetivos operacionais; e, construir um processo de comunicação que permita a todos os níveis organizacionais identificar de forma clara e holística os objetivos que a organização está idealizando. Segundo Gripa e Carvalho (2019) verifica-se que a integração da cadeia de suprimentos possui relação positiva com o desempenho da empresa no que diz respeito aos aspectos estratégicos, organizacionais, de informação e de mercado.

Entretanto, a validade de usar indicadores subjetivos de desempenho tem sido demonstrada como alternativa viável para o caso de inexistência de dados secundários confiáveis (PERIN; SAMPAIO, 1999) o bem a impossibilidade de obtê-los. Conforme comenta Hoque (2005) os motivos pelos quais geralmente são escolhidas as medidas subjetivas ocorrem porque uma parcela significativa de pequenas empresas não possui ou dispõe de poucas informações objetivas, tornando quase que impossível conferi-las com precisão.

Neste estudo, escolheu-se utilizar medidas subjetivas de desempenho, trabalhando com a percepção dos gestores dos hotéis. Esta decisão se baseia no fato de que este constructo constitui a variável dependente no modelo e sua mensuração, como um valor em relação aos concorrentes mais próximos, é apropriada para estimar as relações que ele tem com a gestão de custos.

\section{METODOLOGIA}

Diante dos critérios adotados, a abordagem do problema foi quantitativa. A avaliação quantitativa compreende organizar, sumarizar, caracterizar e interpretar os dados numéricos (MARTINS; THEÓPHILO, 2007). Em relação ao objetivo, classifica-se como um estudo descritivo. Para Vergara (1998) os objetivos da pesquisa 
descritiva se referem à obtenção de informações sobre um fenômeno ou sobre determinada população e à descrição de suas características. No que tange aos procedimentos técnicos, foi do tipo levantamento, que tem como objetivo contribuir para o conhecimento de uma área particular de interesse através da coleta de dados sobre indivíduos ou sobre o ambiente destes (TREZ; MATOS, 2006).

O material para o estudo foi obtido por meio de um questionário de autopreenchimento, enviado via e-mail, o qual foi respondido pelos gestores de hotéis de duas cidades da Região Sul do Brasil: Balneário Camboriú e Itajaí. Balneário Camboriú, localiza-se a $80 \mathrm{~km}$ de Florianópolis, capital do Estado de Santa Catarina/Brasil. A cidade é considerada turística e recebe, de dezembro a março, aproximadamente 1,5 milhões de turistas (SANTUR, 2017). É um município com ótima infraestrutura urbana, a quarta melhor cidade do Brasil para se viver (IBGE, 2019). Itajaí, por sua vez, fica distante 94 km da capital catarinense. É uma cidade com muitas praias, ampla área rural e belas paisagens naturais o que atrai turistas de várias localidades nacionais $\mathrm{e}$ internacionais (IBGE, 2019).

Escolheram-se hotéis das categorias econômico, turístico e superior, que na antiga classificação brasileira correspondiam a dois, três e quatro estrelas respectivamente. A população esteve composta por 32 hotéis que se enquadravam nestas categorias, resultando em uma amostra de 26 respondentes, representando $81 \%$.

O instrumento estava organizado em quatro blocos. No primeiro se recolheram informações dos respondentes e sobre os hotéis. No segundo se dispuseram quatro questões referidas a custos. Perguntava-se sobre o método utilizado para avaliá-los, o critério adotado para estabelecer os preços, os principais custos do hotel e a respeito da utilidade que tinham as informações sobre custos.

No terceiro bloco, usando uma escala de concordância de sete pontos, se dispuseram oito asseverações sobre práticas de custos. Nelas tratavam-se os seguintes assuntos: 1) realização do planejamento estratégico e orçamentário com acompanhamento mensal; 2) fornecimento de informações da contabilidade de custos sobre a margem bruta; 3) fornecimento de informações da contabilidade de custos sobre a margem de contribuição; 4) planejamento de atividades com orçamento detalhado; 5) acompanhamento dos custos efetivamente incorridos e comparação com o orçado; 6) avaliação da contribuição dos clientes para o resultado financeiro; 7) uso das informações da contabilidade de custos para o planejamento, gestão e controle; e, 8) uso associado das informações de custos com a contabilidade de custos para o planejamento, gestão e controle.

Por fim, no quarto bloco se levantaram dados sobre o desempenho, mensurado de modo subjetivo, em relação ao concorrente mais próximo. Utilizou-se, da mesma forma que no bloco anterior, uma escala de concordância de sete pontos. Nela o respondente deveria assinalar se o hotel que gerencia tinha uma melhor performance nos seguintes aspectos: 1) no lucro líquido; 2) nas vendas totais; 3 ) na realização dos resultados financeiros; 4) no cumprimento das metas de pessoal e emprego; 5) no cumprimento das metas de satisfação do cliente; 6) na retenção de clientes; e, 7) no desempenho geral.

Os dados colhidos foram organizados em uma planilha eletrônica Excel $^{\oplus}$ sendo feitos os préprocessamentos sugeridos em Hair Jr. et al. (2009). Inicialmente, se quantificaram 38 dados omissos, mas como sua distribuição não se associava a nenhum padrão os dados faltantes foram preenchidos com o valor da mediana do item em que se registrou a omissão. Logo, avaliaram-se os outliers usando a função gráfica BoxPlot do software Statistica ${ }^{\oplus}$, com a que foram reconhecidos 49 que se optou por manter ao não se reconhecer padrão na sua distribuição.

A seguir, foram calculadas a média, desvio padrão, assimetria, curtose e coeficiente de variação (CV). Possibilitando-se assim fazer a análise descritiva das variáveis. Por outra parte, segundo Finney e DiStefano (2006) se a assimetria e a curtose não ultrapassarem em módulo os valores de 2 e 7 , respectivamente, as distribuições dessas variáveis podem ser consideradas quase normais. Por fim, os dados obtidos analisaram-se estatisticamente empregando a Anova com a análise de correlação de Spearman e do teste de Tukey. 


\section{ANÁLISE DOS RESULTADOS}

Esta seção do artigo apresenta os resultados e as respectivas análises.

\subsection{Perfil dos Hotéis e dos Respondentes}

Inicialmente se analisou o perfil dos hotéis conforme Quadros 1 e 2, evidenciando-se o número DE unidades habitacionais e a área de atuação.

Quadro 1 - Unidades habitacionais.

\begin{tabular}{|l|l|l|l|}
\hline Unidades Habitacionais & Itajaí & $\begin{array}{l}\text { Balneário } \\
\text { Camboriú }\end{array}$ & Total \\
\hline Até 49 Uh & 3 & 4 & 7 \\
\hline De 50 a 100 Uh & 6 & 7 & 13 \\
\hline Acima de 100 Uh & 2 & 4 & 6 \\
\hline Total & 11 & 15 & 26 \\
\hline
\end{tabular}

Fonte: Dados da pesquisa (2018).

Conforme apresentado no Quadro 1, a maioria dos hotéis analisados em Itajaí e Balneário Camboriú, possuem entre 50 e 100 unidades habitacionais, ou seja, ambas as cidades possuem, na maioria, hotéis de médio porte.

Quadro 2 - Área de atuação.

\begin{tabular}{|l|l|l|l|}
\hline Área de Atuação & Itajaí & $\begin{array}{l}\text { Balneário } \\
\text { Camboriú }\end{array}$ & Total \\
\hline Totalmente Negócios & 1 & 0 & 1 \\
\hline Predominante Negócios & 3 & 2 & 5 \\
\hline Negócios e Lazer & 7 & 8 & 15 \\
\hline Predominante Lazer & 0 & 2 & 2 \\
\hline Totalmente Lazer & 0 & 3 & 3 \\
\hline Total & 11 & 15 & 26 \\
\hline
\end{tabular}

Fonte: Dados da pesquisa (2018).

Como se pode observar no Quadro 2, a maioria dos hotéis analisados em Itajaí e Balneário Camboriú, possuem uma área de atuação igualmente em negócios e lazer. Porém, observa-se ainda que as duas cidades possuem enfoque de atuação em sua maioria diferentes.

Em relação ao perfil dos respondentes, os resultados encontrados mostram que ocorre a predominância do gênero masculino, representando $58 \%$ dos respondentes. Destaca-se também, que o tempo de serviço da maioria é de até 5 anos e apenas 4 entrevistados possuem mais de 10 anos de serviço.

\subsection{Custos, Formação do Preço e Desempenho}

Com relação às variáveis o primeiro tratamento foi fazer uma análise descritiva calculando a média, desvio padrão, assimetria e curtose. Os resultados desses processamentos se exibem no Quadro 3, onde se podem observar os valores obtidos as práticas de custo e o desempenho. 
Quadro 3 - Estatísticas descritivas prática de custos (PC) e desempenho organizacional (DO).

\begin{tabular}{|l|l|l|l|l|l|}
\hline Item & Média & $\begin{array}{l}\text { Desvio } \\
\text { Padrão }\end{array}$ & Assimetria & Curtose & CV \\
\hline PC1 & 6,30 & 0,8038 & $-0,8939$ & $-0,0182$ & 0,1275 \\
\hline PC2 & 5,24 & 1,3658 & $-0,2108$ & $-0,9904$ & 0,2609 \\
\hline PC3 & 5,31 & 1,4029 & $-0,3913$ & $-1,0320$ & 0,2643 \\
\hline PC4 & 6,63 & 0,6563 & $-2,0847$ & 5,4409 & 0,0989 \\
\hline PC5 & 5,84 & 1,0774 & $-0,7468$ & 0,2922 & 0,1846 \\
\hline PC6 & 6,23 & 0,7694 & $-0,4211$ & $-1,1962$ & 0,1235 \\
\hline PC7 & 5,35 & 1,3433 & $-0,4352$ & $-0,7493$ & 0,2512 \\
\hline PC8 & 5,25 & 1,3551 & $-0,3287$ & $-0,9147$ & 0,2579 \\
\hline D01 & 5,90 & 1,0599 & $-1,0059$ & 0,8249 & 0,1796 \\
\hline DO2 & 5,92 & 0,9510 & $-1,2552$ & 2,1479 & 0,1607 \\
\hline D03 & 5,97 & 0,9064 & 0,0680 & $-1,7876$ & 0,1519 \\
\hline D04 & 5,76 & 0,7728 & 0,1206 & $-0,4114$ & 0,1342 \\
\hline D05 & 6,61 & 0,5374 & $-0,9207$ & $-0,2453$ & 0,0813 \\
\hline DO6 & 6,02 & 0,8506 & $-0,0469$ & $-1,6197$ & 0,1412 \\
\hline D07 & 5,79 & 1,2115 & $-0,6287$ & $-0,6381$ & 0,2093 \\
\hline$*$ & $*$ & $*$ & $*$ & $*$ & $*$ \\
\hline
\end{tabular}

Fonte: Dados da pesquisa (2018).

Em relação às práticas de custos a maior média $(6,63)$ se obteve para o item PC4, referida ao planejamento das atividades do hotel segundo um orçamento detalhado dos custos. Para o desempenho a média mais alta foi para o item DO5 $(6,61)$ que trata de dar cumprimento às metas de satisfação do cliente. Quando se avalia a relação entre o desvio padrão e a média, isto é, quando se calcula o coeficiente de variação, se observa que a maior variabilidade se constata para a assunção de riscos.

Quanto aos valores calculados da assimetria e curtose da base de dados completa apenas o relativo ao planejamento de atividades com orçamento detalhado (PC4) ultrapassa, em pouco mais de oito centésimos, o valor definido por Finney e DiStefano (2006) para a assimetria.

Antes de avaliar se existe associação entre os constructos, fizeram-se os testes de normalidade de Kolmogorov-Smirnov com os escores fatoriais gerados das dimensões das práticas de custos e do desempenho. Devido a que todos os resultados foram significativos, indicando falta de normalidade, as relações foram aferidas com o coeficiente de correlação de Spearman. O resultado obtido se exibe Quadro 4, onde se mostram o valor do coeficiente e sua significância.

Quadro 4 - Coeficientes de correlação de Spearman entre os escores fatoriais (EF) da prática de custos (PC) e desempenho organizacional (DO).

\begin{tabular}{|l|l|l|l|}
\hline \multicolumn{2}{|l|}{} & EF-PC & EF-DO \\
\hline EF-PC & & 1 & ns \\
\hline EF-DO & & $-0,042$ & 1 \\
\hline
\end{tabular}

Fonte: Dados da pesquisa (2018).

Confirma-se que a prática de custos não tem correlação com o desempenho.

A seguir se efetuaram as Anovas com o método de custo como preditor. Os únicos métodos assinalados pelos respondentes foram: absorção (52), variável (51) e baseado em atividade (ABC) (9). Os achados corroboram com Van Der Merwe (2009), o qual verificou que diversas empresas apresentam dificuldades na implantação e manutenção do ABC. Zanievicz et al. (2013), por sua vez, orientam que as organizações devem utilizar os métodos de custeio como ferramenta importante para o processo de gestão, fornecendo informações essenciais para a tomada de decisões. 
Para as práticas de custos não se verificaram diferenças nas comparações simultâneas na Anova usando como preditor categórico o método de custos dos hotéis. Já ao realizar a Anova com os escores fatoriais do desempenho o resultado da comparação simultânea confirma que há diferenças $(F(2,109)=6,7729, p=$ 0,00169). E o teste de Tukey para número desigual comprova que as médias maiores foram daqueles hotéis que usam o método absorção e baseado em atividade, as que são estatisticamente iguais. No entanto, só a média dos que empregam absorção foi maior ao $5 \%$ daquela calculada para os que utilizam o custeio variável $(p=0,0084)$, sendo a média do baseado em atividade maior apenas com $10 \%$ de significância $(p=0,0828)$. Estes resultados diferem da pesquisa de Zanin, Dal Magro e Mazzioni (2019), os quais investigaram 41 empresas de distintas atividades e os achados indicaram que o método de custeio variável é o mais utilizados pelas entidades estudadas.

Ao utilizar como preditor categórico o modo em que os hotéis fixam os preços, que das opções apresentadas só foram assinaladas as que se referem a fixar o valor com base no custo total (65), considerando o valor do mercado (19) e em função dos preços praticados pela concorrência (28), se constatou que não há diferença para as práticas de custos. No entanto, ao processar os dados do desempenho se verificam diferenças na comparação simultânea $(F(2,109)=6,0548, p=0,00321)$. Na comparação pareada, usando o teste de Tukey para número desigual, se confirma que os hotéis que usam o valor do mercado para estabelecer os preços das diárias são os que apresentam as médias maiores do que os que se baseiam no custo total $(p=0,018)$, mas igual aos que se baseia no preço praticado pela concorrência. Neste sentido, Planagumá e Julve (2012), destacam que analisar a concorrência para a precificação perpassa a compreensão da estrutura de mercado na qual a empresa opera, ao passo que influencia tanto o lado da demanda e oferta, quanto aos custos a serem incorridos na manutenção no mercado. Para Zanin, Dal Magro e Mazzioni (2019, p. 8), “[...] o acompanhamento no preço da concorrência pode trazer discussões que fazem com que os gestores façam adaptações, mantendo a qualidade e reduzindo custos".

Nas outras duas questões relativas a custos se solicitava aos gestores que ordenassem segundo a importância dos custos atribuída pelo hotel. Uma se referia aos custos diretos, indiretos e em publicidade e propaganda. Na outra questão, se solicitava ordenar por importância quanto aos usos dos custos para a gestão. Em ambas as questões só houve dois tipos de ordenamento. Para a primeira questão as ordens foram: (1) custos diretos, indiretos e publicidade e propaganda; e, (2) custos diretos, publicidade e propaganda, e custos indiretos. Na categoria (1) se contabilizaram vinte e oito hotéis e na (2) oitenta, sendo que três questionários estavam sem resposta. Jung e Dall'agnol (2016) explicam que um hotel gera gastos menores com materiais, elevados com mão de obra e custos fixos expressivos em razão da depreciação do imóvel e dos equipamentos.

$\mathrm{Na}$ outra questão que se solicitava ordenar as respostas uma ordem foi: 1) definir preços de hospedagem; 2) admitir/demitir e qualificar pessoal; 3) decidir sobre descontos no preço de hospedagem; e, 4) tomar decisão para novos investimentos no imobilizado. Planagumá e Julve (2012) salientam que todos esses elementos são importantes e devem ser criteriosamente analisados para o estabelecimento de preços, principalmente para a criação de promoções de acordo como tempo de estadia, antecedência da reserva, aproveitamento de dias ociosos e de como reverter reservas não efetivadas, entre outros.

\section{CONSIDERAÇÕES FINAIS}

Entre os temas mais estudados no âmbito da administração estratégica encontra-se o desempenho organizacional e na sua análise têm sido utilizadas diversas aproximações. Portanto, nos debates sobre estratégia, teoria das organizações e empreendedorismo, cada vez mais incluem na agenda que o desempenho organizacional e a sustentabilidade dos negócios são influenciados pela capacidade de empreender e inovar. A gestão dos custos tornou-se assim um tema relevante e significativo para o desempenho empresarial, particularmente quando há incerteza ambiental e nos ambientes competitivos e globalizados.

Com base nos aspectos assinalados o presente estudo buscou avaliar a relação entre o desempenho organizacional e o gerenciamento dos custos dos hotéis. Julgou-se importante avaliar como os métodos de 
custos e de precificação podem influenciar naqueles constructos. Confirma-se que a prática de custos não tem correlação com o desempenho.

Verificou-se que ao trabalhar com a formação do preço da diária se constata que os hotéis que realizam a precificação baseada nos valores de mercado são os que têm melhor desempenho.

Futuros estudos da indústria da hospitalidade, incluindo outras variáveis que têm sido assinaladas como influenciando a relação entre a orientação estratégica dos hotéis e o desempenho, como por exemplo, a munificência ambiental (CARVALHO, 2011), poderão trazer novas informações para o setor. Portanto, se sugere dar continuidade a esses trabalhos, considerando a influência do ambiente de negócios em situações de alta e baixa temporada turística.

\section{REFERÊNCIAS}

BEULKE, R.; BERTÓ, D. J. Estrutura e análise de custos. São Paulo: Saraiva, 2001.

BORTOLUZZI, S. C.; ENSSLIN, S. R.; ENSSLIN, L. Avaliação de desempenho dos aspectos tangíveis e intangíveis da área de mercado: estudo de caso em uma média empresa industrial. Revista Brasileira de Gestão de Negócios, v. 12, n. 37, p. 425-446, 2010.

BRANDT, E.; KROENKE, A.; PLETSCH, C. Efeitos da gestão familiar na avaliação de desempenho da empresa: evidências do Brasil. Revista Catarinense da Ciência Contábil, v. 17, n. 52, p. 41-55, 2018.

BRUNI, A. L.; FAMÁ, R. Gestão de custos e formação de preços: com aplicações na calculadora HP 12C e Excel. 3. ed. São Paulo: Atlas, 2004.

CARVALHO, C. E. Relacionamento entre ambiente organizacional, capacidades, orientação estratégica e desempenho: um estudo no setor hoteleiro brasileiro. Tese (Doutorado) - Programa de Pós-Graduação em Administração. Universidade do Vale do Itajaí - Univali, Biguaçu/SC, 2011.

CASTILLO, G. G.; QUINTERO, J. A. J. Retos estratégicos de la indústria hotelera española del siglo XXI: horizonte 2020 em países emergentes. Tourism \& Management Studies, v. 9, n. 2, p. 13-20, 2013.

CHAKRAVARTHY, B. S. Measuring strategic performance. Strategic Management Journal, v. 7, n. 5, p. $437-$ $447,1996$.

FINNEY, S. J.; DISTEFANO, C. Non-normal and categorical data in structural equation modeling. In HANCOK, G. R.; MUELEER, R. O. Structural equation modeling: a second course. Charlotte, NC: Information Age Publishing, 2006.

GRIPA, S.; CARVALHO, L. C. Integração externa e capacidade de inovação organizacional moderada pelo nível de confiança. Revista Eletrônica de Ciência Administrativa, v. 19, n. 1. p. 85-104, 2019.

GUNASEKARAN, A.; KOBU, B. Performance measures and metrics in logistics and supply chain management: a review of recent literature (1995-2004) for research and applications. International Journal of Production

Research, v. 45, n. 12, p. 2819-2840, 2007.

HAIR Jr., J. F. et al. Análise multivariada de dados. 6. ed. Porto Alegre: Bookman, 2009.

HANSEN, D. R.; MOWEN, M. M. Gestão de custos: contabilidade e controle. São Paulo: Pioneira Thomson Learning, 2001.

HOQUE, Z. Linking environmental uncertainty to non-financial performance measures and performance: a research note. The British Accounting Review, v. 37, p. 471-481, 2005.

IBGE. Cidades. Disponível em: https://cidades.ibge.gov.br/brasil/sc/itajai. Acesso em: 20 set. 2019.

IGARASHI, D. C. C. et al. A qualidade do ensino sob o viés da avaliação de um programa de pós-graduação em contabilidade: proposta de estruturação de um modelo híbrido. RAUSP, v. 43, n. 2, p. 117-137, 2008. 
JUNG, P.; DALL'AGNOL , R. M. formação de preços em hotelaria: um estudo de caso. Revista Turismo - Visão e Ação - Eletrônica, v. 18, n. 1, p. 106-133, 2016.

KOLIVER, O. Contabilidade de custos. Curitiba: Juruá, 2009.

LEITÃO, C. R. S.; SILVA, J. D. G. Utilização do custeio variável no gerenciamento de hotéis: uma pesquisa no setor hoteleiro no nordeste brasileiro. Revista Contabilidade Vista \& Revista, v. 17, n 13, p, 25- 43, 2006.

LEITE, A. F. R.; LAMAS, S. A.; NÓBREGA, V. R. M. Sistemas de gestão ambiental e competitividade: uma análise de múltiplos casos em meios de hospedagem de Natal - RN. Revista Turismo - Visão e Ação, v. 21, n. 1, p. 66-80, 2019.

LUNKES, R. J. Informações de custos: um estudo em empresas hoteleiras na cidade de Florianópolis/SC. Turismo em Análise, v. 20, n. 2, p. 345-368, 2009.

MACEDO, M. A. S.; CORRAR, L. J. Análise do desempenho contábil-financeiro de seguradoras no Brasil no ano de 2007: um estudo apoiado em análise hierárquica (AHP). Contabilidade Vista \& Revista, v. 21, n. 3, p. 135 $165,2010$.

MARTINS, G. A.; THEÓPHILO, C. R. Metodologia da investigação científica para ciências sociais aplicadas. São Paulo: Atlas, 2007.

MINISTÉRIO DO TURISMO. Turismo injetou US\$ 163 bilhões no Brasil em 2017. Disponível em: http://www.turismo.gov.br/\%C3\%BAltimas-not\%C3\%ADcias/1 1037-turismo-injetou-us\$-163-bilh\%C3\%B5esno-brasil-em-2017.html. Acesso em: 20 set. 2019.

NEELY, A.; GREGORY, M.; PLATTS, K. Performance measurement system design: a literature review and research agenda. International Journal of Operations \& Production Management, v. 25, n. 12, p. 1228$1263,2005$.

PLANAGUMÁ, L. P.; JULVE, J. G. Gestión de precios en un sistema de revenue management hoteleiro en línea. Pasos: Revista de Turismo y Patrimonio Cultural, v. 10, n. 5, p. 511-520. 2012.

PELHAM, A. M.; WILSON, D. T. A longitudinal study of the impact of market structure, firm structure, strategy, and market orientation culture on dimensions of small- firm performance. Journal of Academy of Marketing Science, v. 24, n.1, p. 27-43, 1996.

PEREZ JUNIOR, J. H.; OLIVEIRA, L. M. de; COSTA, R. G. Gestão estratégica de custos. 4. ed. São Paulo: Atlas, 2005.

PERIN, M. G.; SAMPAIO, C. H. Performance empresarial: uma comparação entre indicadores subjetivos e objetivos. In:ENCONTRO ANUAL DA ASSOCIAÇÃO DE PÓS-GRADUAÇÃO E PESQUISA EM ADMINISTRAÇÃO (ANPAD), 23,. 1999. Foz do Iguaçu. Anais [...]. Foz do lguaçu, 1999.

RAMOS, M. S.; SOUZA, P. A. R. A. Consolidação de uma medida para análise do desempenho operacional e financeiro em microempresas do setor de hospedagem. Revista Hospitalidade, v. 15, n. 2, p. 41-59, 2018.

SANTOS, M. FLORES, L. C. Formação de preço dos hotéis turísticos da Cidade de São Luís/Maranhão. Rev. Bras. Pesq. Tur. São Paulo, v. 11., n. 1, p.133-153, 2017.

TREZ, G.; MATOS, C. A. de. A influência da ordem das questões nos resultados de pesquisas surveys. In: ENCONTRO ANUAL DA ASSOCIAÇÃO DE PÓS-GRADUAÇÃO E PESQUISA EM ADMINISTRAÇÃO (ANPAD), 29,. 2006. Salvador. Anais [...]. Salvador, 2006.

VAN DER MERWE, A. Debating the principles: $A B C$ and its dominant principle of work. Cost Management, $v$. 23, n. 5, p. 20-28, 2009.

VERGARA, S. C. Projetos e relatórios de pesquisa em administração. São Paulo: Atlas, 1998. 
VIANA FILHO, J. R.; GOMES, K. L. S.; SOUZA, T. C. Custos e formação de preço como estratégia competitiva: um estudo em indústrias de suplementação animal na cidade de Rondonópolis-MT (Brasil). In: XII CONGRESSO INTERNACIONAL DE COSTOS. 7,. 2011. Punta del Este. Anais [...]. Punta del Este, 2011.

ZANIEVICZ, M.; BEUREN, I. M.; SANTOS, P. S. A.; KLOEPPEL, N. R. Métodos de Custeio: uma meta-análise dos artigos apresentados no Congresso Brasileiro de Custos no período de 1994 a 2010. Revista Brasileira de Gestão de Negócios, v. 15, n. 49, p. 601-616, 2013.

ZANIN, A.; DAL MAGRO, C. B.; MAZZIONI, S. Características organizacionais e a utilização da gestão de custos no processo decisório. Revista Catarinense da Ciência Contábil, v. 18, p. 1-19, 2019. 